\title{
CORRECTING LABIAL THICK AND HIGH ATTACHED FRENUM (clinical observation)
}

\author{
Silvia Krusteva ${ }^{1}$, Mariana Dimitrova ${ }^{2}$, Hristo Daskalov ${ }^{3}$, Stiliana Krusteva ${ }^{4}$ \\ 1) Department of Orthodontics, \\ 2) Department of Pediatric Dentistry, \\ 3) Department of Oral Surgery, \\ 4) Student, \\ Faculty of Dental Medicine, Medical University - Plovdiv, Bulgaria.
}

\begin{abstract}
Labial thick and high attached maxillary frenum is commonly regarded as contributing etiology for maintaining midline diastema and upper jaw delayed development. The surgical modalities used to solve this problem are known to be quite stressful for children. Dental lasers have recently been increasingly used to treat wide variety of problems in medicine.

AIM: Using a high energy diode laser to remove a short, high attached frenum of the upper lip and present the results of the procedure.

MATERIAL AND METHODS: We performed frenectomy in 10 randomly selected patients of both sexes aged 7-9 years with short, thick frena of the upper lip. A Picasso soft tissue diode laser, class IV, power output $7 \mathrm{~W}$, л-810 nm was used for the procedure.

RESULTS AND DISCUSSION: The healing process was uneventful, painless and without edemas developing in the soft tissues. No inflammation was found in the treated tissues. The children undergoing the procedure showed no fear. This was the reason why we preferred to use lasers as a modern therapeutic modality for soft tissue correction in the mouth.

CONCLUSION: Using lasers to remove short, high attached maxillary labial frenum has the benefit of inducing less stress in children than that they experience if anaesthesia and surgery are administered. Anaesthesia with topical anaesthetics is used in the procedure. The postoperative period is free of pain and far from severe. This makes this technique particularly useful for children.
\end{abstract} laser.

Key words: maxillary frenum, frenectomy, diastema,

\section{INTRODUCTION}

Short, thick maxillary labial frena that have wide attachment base are commonly considered an etiologic factor for a diastema and delayed upper jaw development.
They can cause gingival recession and hamper orthodontic treatment. (2)

With low attached frena getting back to normal condition is expected after the eruption of the permanent incisors and canines. But if frena are short and thick with wide attachment bases there might be a risk of periodontal tissue damage. (4) In such cases the correction procedure should involve the correction of the attachment site and the length of the frenum which usually is achieved through surgery. Conventional surgical methods usually involve injection anesthesia. And surgical intervention are apparently a source of high stress for children.

Dental lasers, because of their wide range of biologic action, have recently been steadily introduced in dental medicine. Low-energy laser radiation is used to stimulate the healing process in soft tissues and bone lesions. (7) High energy laser radiation is used to remove some formations and lesions on mouth mucosa that require a surgical intervention. $(5,6,11)$ However it is still rarely used in orthodontics. $(8,9)$

But lasers can be quite useful in the adjustment of short, thick maxillary frenum. The technique requires the use of very small amount of topical anaesthetics and has shown to induce less stress in children during the procedure and after that. (1)

Different types of high energy lasers using different wave length can be used for the purpose. $(3,10)$

Aim: Using a high energy diode laser to remove a short, thick upper lip frenum with wide attachment base and present the results of the procedure.

\section{MATERIAL AND METHODS.}

We performed frenectomy in 10 randomly selected patients of both sexes (age range 7-9 years) with short labial frena with wide attachment base (Fig. 1). 


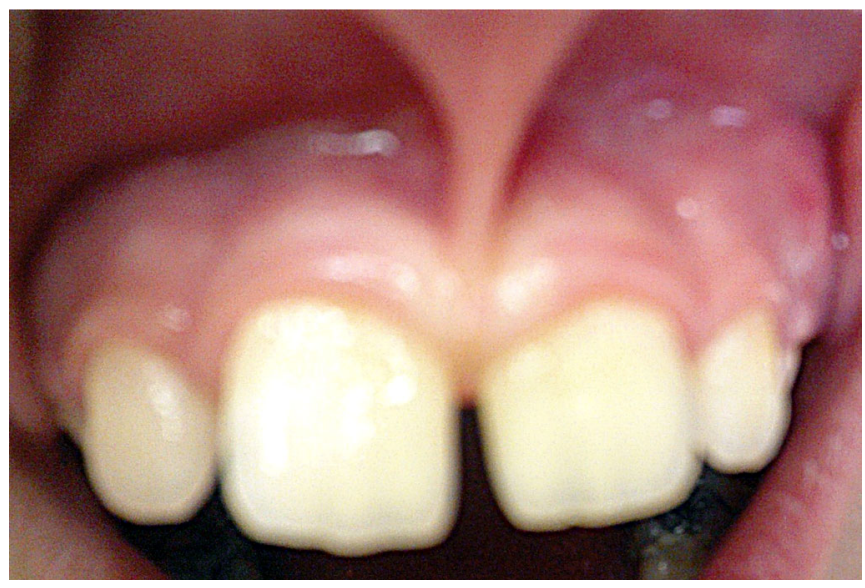

Fig. 1. Short frenum with wide attachment base.

Local anaesthesia was used in performing the procedure. A Picasso diode laser, class IV, power output 7 $\mathrm{W}$, л-810 $\mathrm{nm}$ designed for work in soft tissues was used (Fig. 2 ). We used one of the inbuilt programmes of the equipment working in impulse mode of work and with power output of $2 \mathrm{~W}$.

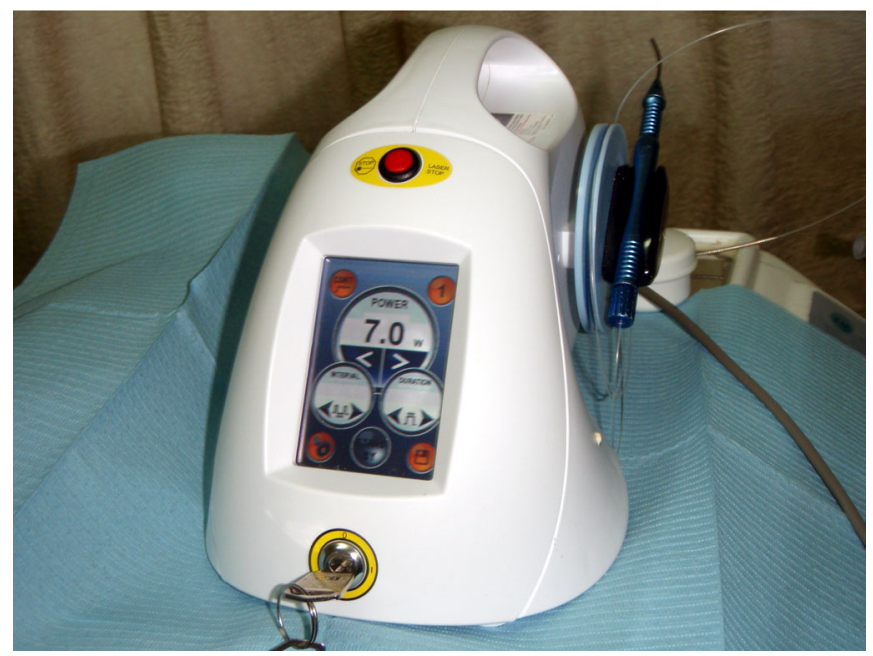

Fig. 2. A soft tissue diode laser.

\section{RESULTS}

We removed the frenum of the upper lip in 10 patients (Figures 3 and 4). The children showed no fear of the procedure. We needed no extra motivation to perform it or injection anesthesia. The control examination the next day after the procedure showed that healing was running a normal course, with no pain and edemas in tissues. No inflammation was found in the treated tissues. There was no need for a special regimen after the procedure. The patients maintained good oral hygiene. There was no coating found around and over the operative field.

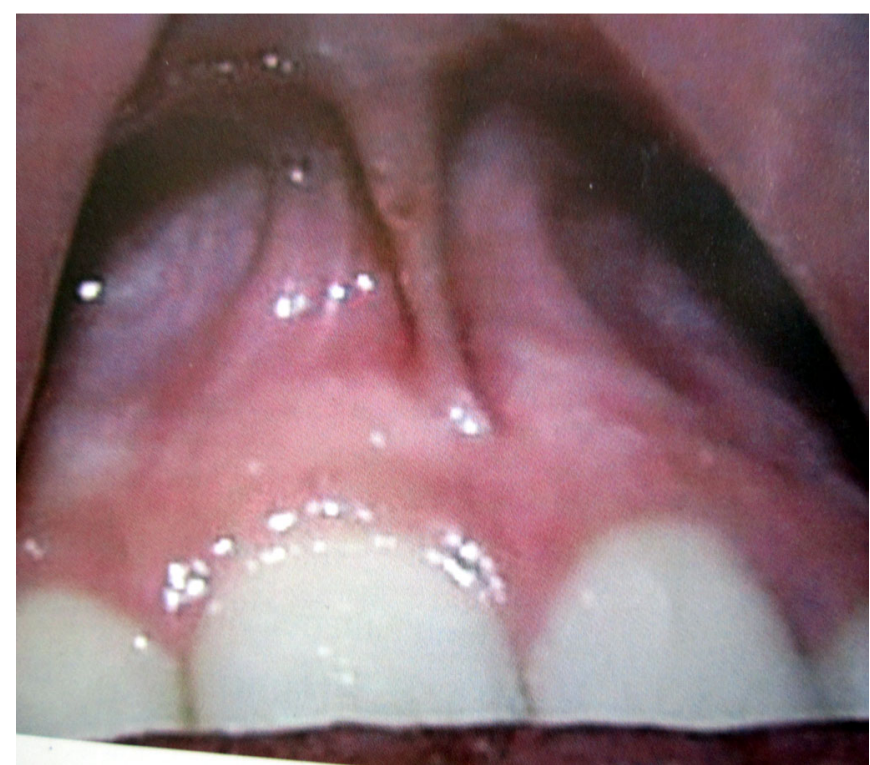

Fig. 3. Patient N.P. (9 years old) before frenectomy.

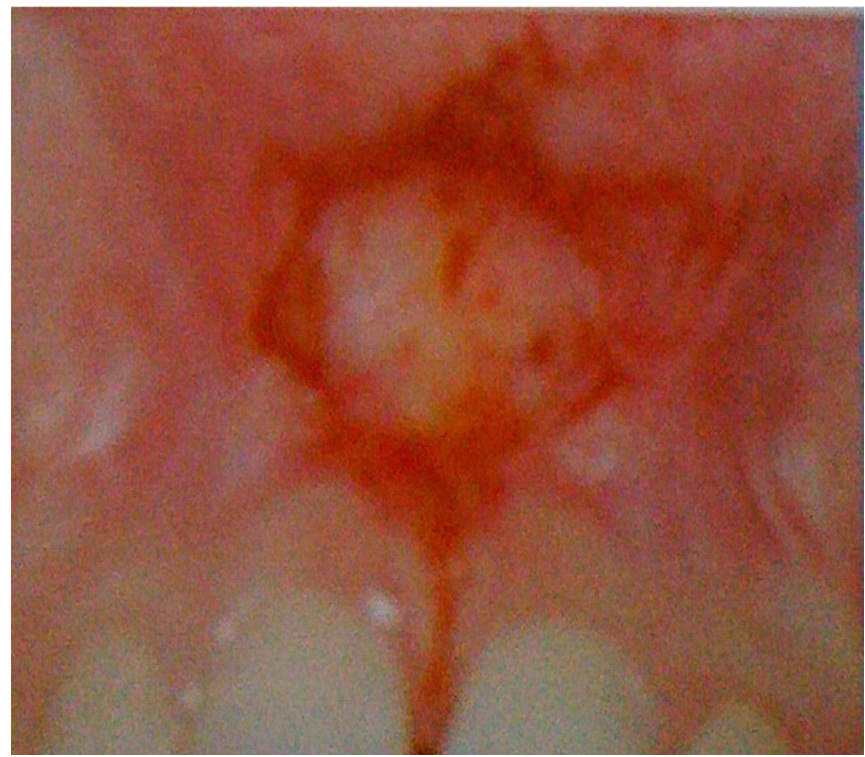

Fig. 4. Patient N.P. (9 years old) after frenectomy.

\section{DISCUSSION}

The laser energy is produced in the laser resonator. A fiber-optic system controlled by a handpiece knob was used to focus it. The light energy is collimated so that it can cut through tissues as hard as hydroxylapatite crystals. The laser beam and the water spray produce hydrokinetic energy which yields clear operative field and extremely precise and straight incision. $(3,5,10)$

Using lasers to remove the maxillary labial frenum reduces patients' discomfort and stress considerably. Healing is faster with less postoperative pain due to the biostimulating effect of the laser. There is no need of 
postoperative management of the wound. The anesthesiaassociated stress and the blood procedure usually so much feared by children are avoided. These factors helps in the orthodontic treatment and makes it faster. Laser energy stimulates the DNA-RNA-Protein system and this increases the mitotic activity of cells. This accelerates the formation and creation of fibroblasts and collagen fibers. The technique stimulates the epithelialization of the surgical wound and regeneration of the nerve fibers. Lasers are antibacterial so infection is very unlikely as many bacterial and viral colonies are destroyed in the procedure. $(1,3,8$ 10) Lymph vessels are sealed, capillaries are constricted, and the homeostasis improves. The lack of post-operative pain is due to the depolarization of the nerve fibres. In this way there is less need for painkilling agents after the frenectomy.
All problems in social activity that could have been raised if conventional surgery were performed are avoided. $(8,9)$ And this was the reason why we preferred to use laser energy as a modern therapeutic modality for correction of short and thick frena of the upper lip with wide attachment base.

\section{CONCLUSIONS}

Using laser energy to remove a short and thick maxillary labial frenum has significant advantages over the conventional surgical methods. It reduces the stress children experience by anesthesia and blood procedure. Anesthesia with topical anesthetics is used in the procedure. The postoperative period is free of pain and far from severe. This makes this technique particularly useful for children.

\section{REFERENCES:}

1. Arnautska Hr, Krumova V, Georgieva T. Correction of short frena using ER, CR: YSGG laser (Waterlase MD). Clinical trial. Orthodontic Review. 2011; 13,2:10-11. [in Bulgarian]

2. Dekova L, Mutafchiev V, Krumova V. Atlas of orthodontic prophylaxis. Medicine and sports, Sofia. 1993;144-149. [in Bulgarian]

3. Lalabonova Hr, Firkova E. Lasers in dentistry. Physical medicine, rehabilitation, health. 2006; 4:4-9. [in Bulgarian]

4. Mutafchiev V, Krumova V, Yordanov V. Orthodontics for general dental practitioner. Nemizida, Sofia. 2003; 211-222. [in Bulgarian]

5. Borstein E. Proper use of Er
YAG lasers and contact sapphire tips when cutting teeth and bone: scientific principles and clinical application. Dent Today. 2004 Aug;23(8):84, 86-89. [PubMed]

6. Lalabonova Hr, Peycheva St, Petrov P. Application of $\mathrm{Nd}-\mathrm{YAG}$ laser treatment for oral leukoplakia. $J$ of IMAB. 2012; 18(4):240-242. [CrossRef]

7. Lalabonova Hr. Low intensity lasers in the surgical protocol if the dental implantology. J of IMAB. 2011; 17(2):104-106. [CrossRef].

8. Sarver DM, Yanosky M. Principles of cosmetic dentistry in orthodontics: Part 2, Soft tissue laser technology and cosmetic gingival contouring. Am J Orthod Dentofacial
Orthop. 2005 Jan;127(1):85-90. [PubMed] [CrossRef]

9. Sarver DM, Yanosky M. Principles of cosmetic dentistry in orthodontics: Part 3, Laser treatments for tooth eruption and soft tissue problems. Am J Orthod Dentofacial Orthop. 2005 Feb;127(2):262-264. [PubMed] [CrossRef]

10. Wigdor HA, Walsh JT Jr, Featherstone JD, Visuri SR, Fried D, Waldvogel JL. Lasers in dentistry. Lasers Surg Med. 1995; 16(2):103133. [PubMed]

11. Yordanova S, Yordanova M, Tomov G, Lalabonova Hr. Er:YAG laser application in orthodontic practice. A case report. J of IMAB. 2011, 17(2):129-131. [CrossRef].

\author{
Corresponding author: \\ Dr. Silvia Krusteva, \\ Department of Orthodontics, Faculty of Dental Medicine, \\ Medical University Plovdiv, \\ 3, Hristo Botev boul., 4000 Plovdiv, Bulgaria. \\ E-mail:dr.krusteva@abv.bg;
}

